\title{
THE CIRCULATORY RESPONSES TO HYPERTHERMIA INDUCED BY RADIANT HEAT ${ }^{1}$
}

\author{
BY O. PREC, 2 R. ROSENMAN, K. BRAUN, ${ }^{3}$ R. HARRIS, S. RODBARD, \\ AND L. N. KATZ \\ (From the Cardiovascular Department, 4 Medical Research Institute, Michael Reese \\ Hospital, Chicago)
}

(Received for publication July 19, 1948)

An elevation of the body temperature evokes many physiological changes, as a direct result of the increased rate of metabolism and the greater demand for oxygen and substrate, and indirectly in warm blooded animals because of the elicitation of thermolytic mechanisms. An understanding of the interrelationships between these factors is of obvious importance in an appreciation of the dynamics of hyperthermia and in the establishment of a rationale for its treatment. Despite many important contributions to this problem, there is a paucity of information concerning the effect of hyperthermia on the cardiac output and the right intracardiac pressures. We have therefore undertaken an analytical study of the circulation in hyperthermia in an effort to assay these adjustments more satisfactorily. Our present experiments have been limited to a study of the changes which occur following exposure to radiant heat since this method of producing hyperthermia seemed to be the simplest, being free from incidental effects produced by pyrogens and by other methods. A few experiments were done with short wave diathermy.

\section{METHOD}

Hyperthermia was induced in nine dogs. Six dogs, anesthetized with sodium pentobarbital, were exposed to radiant heat from several light bulbs until the body temperatures (about $38^{\circ} \mathrm{C}$ ) gradually increased to $42^{\circ} \mathrm{C}$ during a two-hour interval. Body temperatures were reduced during the following one- to two-hour periods by using cold wet cloths applied to the body and by draft-producing electric fans. Temperatures were obtained from a thermometer placed deeply in the rectosigmoid area. A mercury manometer attached to a

1 Aided in part by a grant from the Department of the Army to the Michael Reese Hospital (Dr. L. N. Katz, responsible investigator).

2 Rockefeller Fellow from Prague, Czechoslovakia.

3 Hadassah Fellow from Jerusalem, Israel.

4 This department is supported in part by the Michael Reese Research Foundation. femoral artery recorded mean arterial blood pressures on a kymograph. Mean pulmonary arterial and right auricular pressures were obtained with saline manometers attached to their respective radio-opaque cardiac catheters. Cardiac output was calculated according to the Fick formula, blood from the pulmonary artery being used as mixed venous blood, and oxygen consumption being recorded with a basal metabolism apparatus attached to the cannulated trachea. Hematocrits of the arterial blood were determined according to the method of Wintrobe. Blood $\mathrm{O}_{2}$ and $\mathrm{CO}_{2}$ analyses were performed by the Van Slyke-Neill technique. A detailed description of these methods is given elsewhere (1). Measurements similar to the above were also obtained in a series of three dogs heated by short wave diathermy, ${ }^{5}$ but unless specified, the results given below refer only to those experiments in which radiant heat was employed. Similar measurements were made on three control anesthetized dogs kept at room temperature.

\section{DISCUSSION OF RESULTS}

\section{Oxygen consumption}

Many studies have demonstrated a close parallel between the rise in body temperature and the increased oxygen consumption (2-4) which accompanies the acceleration of cellular metabolism during fever. In our experiments (Figure 1) an average increase of $57 \%$ was observed at a body temperature of $42^{\circ} \mathrm{C}$, the greatest increase being $100 \%$ in one instance. During the cooling period oxygen consumption decreased simultaneously with the fall in body temperature and returned to control levels as the temperature of the animal again reached $38^{\circ} \mathrm{C}$. In the control series only slight and insignificant changes in oxygen consumption took place.

\section{Respiration and content of blood gases}

The production of hyperthermia was accompanied by an increase in respiratory rate and

5 The Burdick Corporation generously supplied the short wave equipment. 


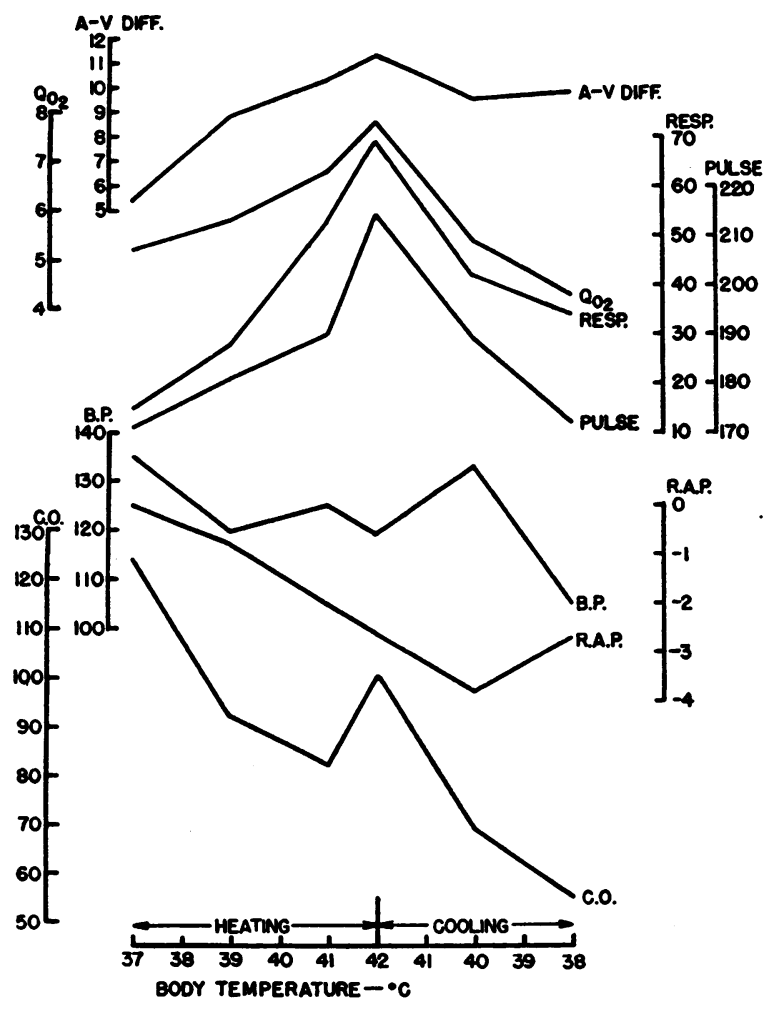

Fig. 1. A Composite Graph of the Average Values of Various Factors during the Heating and CoolING oF Six DogS

A-V Diff. represents the arteriovenous oxygen difference (vols.\%); $\mathrm{QO}_{2}$, the oxygen consumption in cc./ kg./min.; Resp. and Pulse are, respectively, the respiratory and pulse rates per minute; B.P., the mean arterial blood pressure in $\mathrm{mm}$. $\mathrm{Hg}$; C.O., the cardiac output in cc./kg./min.; and R.A.P., the mean right auricular pressure in $\mathrm{cm}$. saline. volume (Figure 1) similar to that which has been reported in all types of naturally occurring fever (2). During recooling the respiratory rate and volume decreased proportionately to the temperature fall. It is of interest to note, however, that greater than normal rates and volumes of respiration persisted even after the conclusion of the cooling period and the return of body temperature to control levels. This effect may have been due to the greater rate of destruction of the anesthetic agent during the febrile period and a consequent heightened activity of the respiratory center. In the control series no significant changes were noted.

Differences in the respiratory response were noted, depending on the type of heating used. With radiant heat the respirations were regular and only slightly decreased in depth. When the fever was produced with short wave diathermy, respirations became shallow and grossly irregular. The hyperpnea was probably due to the increased $\mathrm{CO}_{2}$ production in the tissues, the increased activity of the respiratory center itself, and the initiation of thermolytic reflexes. It has been reported that extreme tachypnea and shallow respiration may seriously interfere with the exchange of alveolar air, and thus decrease the arterial oxygen content $(3,5)$. However, the slope of the oxygen consumption curve in our experiments indicated that the diffusion of oxygen in the lungs was not impaired when radiant heat was employed. With diathermy, the slope of the curve was highly irregular. It was because of this

TABLE I

Oxygen content of arterial and venous blood (volume per cent)

\begin{tabular}{|c|c|c|c|c|c|c|c|c|c|c|c|c|}
\hline \multirow{2}{*}{$\begin{array}{c}\text { Body } \\
\text { tempera- } \\
\text { ture }\end{array}$} & \multicolumn{2}{|c|}{ Dog no. H1 } & \multicolumn{2}{|c|}{ Dog no. $\mathrm{H} 2$} & \multicolumn{2}{|c|}{ Dog no. H3 } & \multicolumn{2}{|c|}{ Dog no. H4 } & \multicolumn{2}{|c|}{ Dog no. H5 } & \multicolumn{2}{|c|}{ Dog no. H6 } \\
\hline & Art. & Ven. & Art. & Ven. & Art. & Ven. & Art. & Ven. & Art. & Ven. & Art. & Ven. \\
\hline $\begin{array}{l}{ }^{\circ} C . \\
36 \\
37 \\
38 \\
39 \\
41 \\
42 \\
40 \\
39 \\
38 \\
37\end{array}$ & $\begin{array}{l}\overline{20.6} \\
\overline{19.7} \\
19 \\
19.7 \\
19 \\
\overline{18.9} \\
-\end{array}$ & $\begin{array}{c}\overline{13.6} \\
\overline{10.4} \\
8 \\
5.7 \\
8.7 \\
\frac{8.7}{-}\end{array}$ & $\begin{array}{l}12.6 \\
11.6 \\
11.7 \\
12 \\
12 \\
= \\
- \\
-\end{array}$ & $\begin{array}{l}6.3 \\
3 \\
2.4 \\
2 \\
1.9 \\
- \\
-\end{array}$ & $\begin{array}{l}-\overline{-} \\
12.8 \\
13 \\
12 \\
12.1 \\
\frac{13}{12.7} \\
-\end{array}$ & $\begin{array}{l}\overline{-} \\
7.5 \\
5.5 \\
2.7 \\
\overline{5} \\
\frac{6.0}{-}\end{array}$ & $\begin{array}{l}24.1 \\
25.1 \\
\frac{-}{23} \\
24.5 \\
25.3 \\
\frac{-}{24.8} \\
\frac{24.6}{24.5}\end{array}$ & $\begin{array}{c}20.8 \\
16.2 \\
\frac{8}{8} \\
9.6 \\
10.1 \\
\frac{-6.3}{3.2}\end{array}$ & $\begin{array}{l}\overline{-} \\
\overline{15.5} \\
\frac{19.4}{\overline{20.3}} \\
\frac{20}{-}\end{array}$ & $\begin{array}{l}\overline{-} \\
\overline{11} \\
\frac{6.3}{7} \\
\frac{4.6}{-}\end{array}$ & $\begin{array}{l}\overline{-} \\
14.9 \\
16 \\
16.2 \\
16 \\
16.4 \\
\overline{15.4} \\
-\end{array}$ & $\begin{array}{l}\overline{-} \\
12.1 \\
12 \\
11.4 \\
10 \\
8.7 \\
\frac{7.9}{-}\end{array}$ \\
\hline
\end{tabular}


irregularity that the results obtained with diathermy were not treated in the present study.

The arterial oxygen content varied only slightly during our experiments with an average decrease of 0.8 vol. $\%$. The large difference in dog $\mathrm{H} 5$ (Table I) was associated with a simultaneous increase in hematocrit. No significant changes were noted in the control series. Others have reported decreases in arterial oxygen content during hyperpyrexia $(3,6)$ with a relatively greater decrease in venous blood oxygen content (3).

The effect of hyperpnea on the $\mathrm{CO}_{2}$ content of the arterial and venous blood should be emphasized. Figure 2 shows that as the respiratory rate increased, the $\mathrm{CO}_{2}$ content of the arterial blood decreased. The curve for venous blood is similar to that of arterial blood but shifted to the right. The primacy of the thermolytic mechanism which is effected chiefly by panting in the dog is seen by the marked reduction of blood $\mathrm{CO}_{2}$ and the consequent alkalotic tendency. Despite this tendency to alkalosis, the respiratory rate continued at high levels.

\section{Arteriovenous oxygen difference}

The oxygen content of the arterial and venous bloods is given in Table $I$. It can be seen from

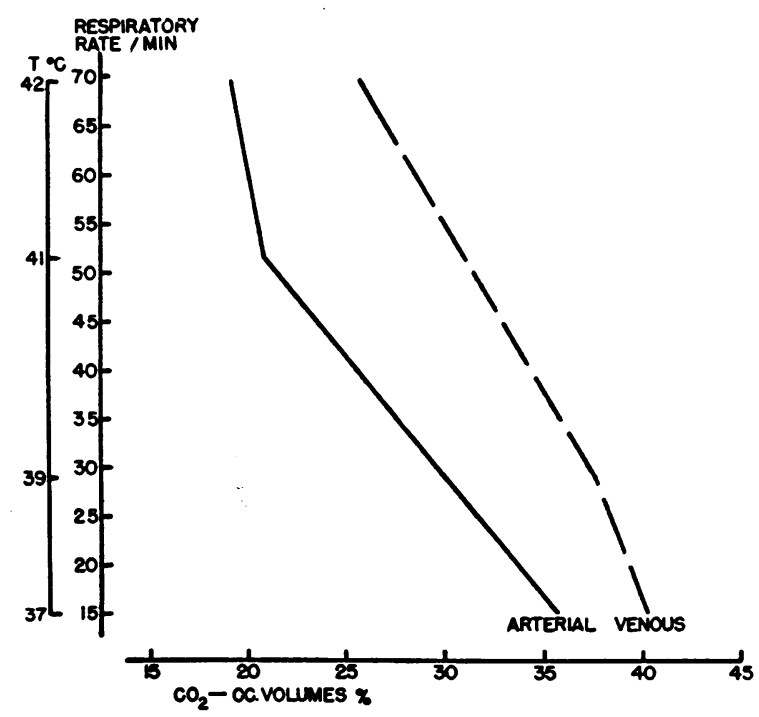

Fig. 2. A Graph Showing the Relationship between the Body Temperature, Respiratory Rate, and the Carbon Dioxide Content (Vols.\%) of Arterial and Venous Blood during the Warming Period from $37^{\circ}$ To $42^{\circ} \mathrm{C}$

$T$ represents temperature. it that the utilization of oxygen increased proportionately to the rise in body temperature despite the progressively reduced cardiac output (Figure 1). The average arteriovenous oxygen difference was 6.1 vol. $\%$ at $36^{\circ}$ to $38^{\circ} \mathrm{C}$ and increased to 11.3 vol. $\%$ at $42^{\circ} \mathrm{C}$, remaining high in some instances or even increasing during the recooling period. The increase in $\mathrm{A}-\mathrm{V}$ oxygen difference was relatively greater than the increase in oxygen consumption. These findings are in general agreement with those of Uyeno (3).

\section{Hematocrit}

Approximately $100 \mathrm{cc}$. of blood were removed and replaced by isotonic saline solution during each experiment. Hematocrits of arterial blood samples showed no consistent trends. During fever it has been reported (7) that there is usually an initial hemodilution with increased blood volume.

\section{Cardiac output}

Two of the most important factors which must be assayed in order to understand the circulatory changes which occur during exposure to radiant heat include the simultaneous measurement of the cardiac output and the blood pressure. In our experiments the cardiac output decreased consistently with fever (Table II) in all but two animals in which a transient rise occurred at the beginning of the warming period. The output began to decrease early or immediately after the heat was applied. In the two dogs $\mathrm{H} 2$ and $\mathrm{H} 4$, the cardiac output decreased markedly while the temperature was rising from $36^{\circ}$ to $38^{\circ} \mathrm{C}$ (from 1396 to $821 \mathrm{cc}$., and from 1300 to $712 \mathrm{cc} . / \mathrm{min}$., respectively). The relatively greater increase in the arteriovenous oxygen difference compared to

TABLE II

Cardiac output cc./kg./min. and body temperature

\begin{tabular}{|c|c|c|c|c|c|c|c|c|c|c|}
\hline \multirow{2}{*}{$\begin{array}{l}\text { Dog } \\
\text { no. }\end{array}$} & \multicolumn{10}{|c|}{ Body temperature $\left({ }^{\circ} \mathrm{C}.\right)$} \\
\hline & 36 & 37 & 38 & 39 & 41 & 42 & 40 & 39 & 38 & 37 \\
\hline H1 & - & 78 & - & 95 & 77 & 64 & 54 & - & 53 & 一 \\
\hline H? & 89 & 52 & 64 & - & - & 57 & died at & & & \\
\hline H3 & - & - & 136 & 82 & 86 & - & 85 & - & 77 & - \\
\hline $\mathrm{H} 4$ & 111 & 64 & - & 41 & 49 & 50 & $\frac{1}{30}$ & 20 & -1 & 12 \\
\hline $\begin{array}{l}\mathrm{H} 5 \\
\mathrm{H} 6\end{array}$ & - & 二 & $\overline{344}$ & $\begin{array}{r}74 \\
166\end{array}$ & $\begin{array}{r}33 \\
163\end{array}$ & $\overline{120}$ & $\begin{array}{l}29 \\
81\end{array}$ & - & $\begin{array}{l}16 \\
75\end{array}$ & - \\
\hline & & & & & 103 & 129 & & & & \\
\hline
\end{tabular}


that of the oxygen consumption accounted for the decreased cardiac output which occurred in the face of increases in oxygen consumption and pulse rate.

Electrocardiographic studies $(2,8)$ and the transitory character of the changes during fever suggest that the conduction system of the heart is apparently not damaged in short-lasting fever. We may therefore assume that the changes in cardiac output during fever were determined primarily by a decreased venous return rather than by cardiogenic factors. The decreased venous return is probably an early result of redistribution of blood which may later be accentuated by the markedly reduced blood volume resulting from the fluid loss consequent to heating. Some decrease in cardiac output was noted in the controls due partly to the anesthetic and partly, perhaps, to the spontaneous fall in body temperature of one to two degrees (1).

During recooling the cardiac output continued to decrease significantly, even after body temperature had fallen to control levels (Table II). This would suggest that the febrile period sets up mechanisms which reduce the cardiac output, and that these mechanisms may persist for a time after the cessation of the heating period.

\section{Blood pressure}

Blood pressure changes seen during the induced fever were variable (Figure 1). In four dogs an initial and progressive fall occurred. In one, no change in pressure occurred and in one there was an initial rise followed by a fall. The greatest fall in pressure was $57 \%$ of the original level. In two of the three dogs heated with short wave diathermy the blood pressure tended to rise and then remained at the higher levels, findings similar to those reported by Wiggers and Orias (9).

Since the blood pressure is the resultant of a number of factors, the effect of heating on each of them must be considered in the interpretation of results. Among the more important are the decreased cardiac output, an increase in the vascular bed due to vasodilation in various portions of the body, and neurogenic factors which tend to increase the peripheral resistance and thus maintain the blood pressure. The apparent contradiction in the latter two factors may be resolved on the basis of regional differences in vascular tone. This mechanism deserves further analysis. In the control series, a slight decrease in blood pressure occurred probably due to the anesthetic and to the spontaneous fall in body temperature (1).

\section{Pulse rate}

A close correlation between body temperature and pulse rate has been shown (2). Acceleration of the pulse rate is effected by the direct action of the increased temperature on the sinus node which remains the pacemaker even during very rapid rates (10). The rate increases as much as 92 beats per minute at $42^{\circ} \mathrm{C}$, averaging 39 (Figure 1 ). No significant changes were noted in the control series. An acceleration of the pulse rate is obviously not necessarily associated with an increase in cardiac output since other factors play more dominant roles (11).

\section{Intracardiac pressures}

The pressure in the right auricle was measured in four dogs and showed steady and substantial decreases (Figure 1). The pressures continued to fall during the cooling period and at the end of the experiments were as low as $4 \mathrm{~cm}$. saline below the control levels. Large variations in both directions were seen in the pulmonary arterial pressure in both the heated and control series. The changes in the right auricular pressures in the control group were inconstant, varying only slightly from control levels.

\section{DISCUSSION}

The data collected during our experiments represent an analysis of the circulatory responses to exposure to an intense radiant heat. The mechanism of the rise in body temperature induced by exposure to radiant heat is essentially that of a prevention of heat loss (12). There is no doubt that adaptation will be different following exposure to different types of heat.

The generalized application of intense radiant heat was followed shortly by a progressive fall in cardiac output, regardless of the elevated body temperature, oxygen consumption and the heart rate. It has too often been assumed that cardiac output invariably increases during fever $(2,10)$. While the output may increase in certain circumstances $(3,4,6)$ recent ballistocardiographic stud- 
ies have failed to demonstrate an increase during fever (13) and others have suggested that the output may be reduced in hyperthermic states (9, 14). Our results demonstrate that in induced fever due to radiant heat, the cardiac output is usually diminished and that this is a dominant factor in the ensuing circulatory changes.

In hyperthermia produced by high external temperature, marked vasodilatation occurs in the cutaneous and other vascular beds (2). Large amounts of blood may therefore be shifted to the periphery, resulting in a decreased volume of blood available for venous return to the heart. This is indicated by the falling venous pressure which we observed in our hyperthermic animals. The increased respiratory activity associated with an excessive internal temperature and the loss of body fluids both contribute to decrease further the effective blood volume. These changes also lead to a reduction in venous return and so to a further reduction in cardiac output, in proportion to the duration and intensity of exposure to radiant heat.

Many explanations have been advanced to explain the circulatory collapse in heat stroke and these have been reviewed recently by Daily and Harrison (4). These include hemoconcentration, reduction of blood volume, increased intracapillary pressure resulting in increased fluid transudation and cardiogenic vascular collapse. Wiggers and Orias (9) have demonstrated a reduction in systolic discharge and a decrease in the force of ventricular contraction when the body temperature rises above $41^{\circ} \mathrm{C}$ due to exposure to radiant heat. Our results suggest that the normal heart is not significantly injured by hyperpyrexia and appears to be able to cope adequately with the venous return from the periphery.

Previous experiments in this laboratory (1) have re-emphasized that both man and animals may undergo prolonged exposure to cold with reduction in body temperature as great as $12^{\circ} \mathrm{C}$ in the dog, with complete recovery in most instances following rewarming. Tolerance to elevated body temperature is therefore considerably less than tolerance to cooling. Thus, in the dog, survival after a rise in temperature of $5^{\circ} \mathrm{C}$ will be rare and even lesser elevations of body temperature may be sufficient to embarrass the cardiovascular system.
When the febrile animal was permitted to lose heat, the body temperature rapidly returned to normal but the cardiac output continued to decrease. Evidently mechanisms initiated during the hyperthermic phase which reduced the cardiac output persisted during the phase of return to normal body temperature. Rational therapy should therefore be directed to measures which would increase the cardiac output to normal values during the cooling phase. Simple reduction of the body temperature to normal obviously would be inadequate since the cardiac output remains markedly reduced and peripheral circulatory failure may result in death.

\section{SUMMARY}

The changes in the cardiovascular system were studied in anesthetized dogs during acute hyperthermia induced by intense radiant heat and during the return of body temperature from $42^{\circ} \mathrm{C}$ to normal.

During the warming period the oxygen consumption increased markedly, rising to about $150 \%$ of normal at $42^{\circ} \mathrm{C}$. The cardiac output was progressively reduced. As a consequence the arteriovenous oxygen difference was incrcased. The blood pressure was maintained at relatively normal levels in the face of an apparent increase in the capacity of the vascular bed and a coincident decreased cardiac output, indicating an active vasoconstriction process. The heart rate increased progressively with hyperthermia and the right auricular pressure tended to fall.

During the recooling period the oxygen consumption, respiratory rate and heart rate returned toward normal levels. The cardiac output and right auricular pressure continued to decline significantly even after the body temperature had returned to control levels. The blood pressure was maintained in most of the animals. No significant changes were found in the pulmonary arterial pressure.

During hyperthermia the heart appears to be able to cope with the venous return. Our experiments therefore suggest that the circulatory changes occurring in acute hyperthermia depend upon (1) an increased demand for blood by the tissues which leads to (2) an increase in the volume of the vascular bed. Since (3) the circulating blood volume and venous return do not in- 
crease proportionately and may even decrease, a marked reduction in cardiac output occurs. (4) If the blood pressure and the circulation are to be maintained vasoconstriction must occur. Failure of the vasomotor centers to compensate for the progressively reduced cardiac output prepares the ground for peripheral vascular collapse.

\section{BIBLIOGRAPHY}

1. Prec, O., Rosenman, R., Braun, K., Rodbard, S., and Katz, L. N., The cardiovascular effects of acutely induced hypothermia on the circulatory system. J. Clin. Invest., 1949, 28, 293.

2. Altschule, M. D., and Freedberg, A. S., Circulation and respiration in fever. Medicine, 1945, 24, 403.

3. Uyeno, K., Studies on the respiration and circulation in the cat. III. Effect of rise of body temperature. J. Physiol., 1923, 57, 203.

4. Daily, W. M., and Harrison, T. R., A study of the mechanism and treatment of experimental heat pyrexia. Am. J. Med. Sc., 1948, 215, 42.

5. Looney, J. M., and Borkovic, E. J., Changes produced on oxygen and carbon dioxide content of arterial and venous blood of brain during diathermy therapy for general paresis. Am. J. Physiol., 1942, 136, 177.
6. Hartman, F. W., Lesions of brain following fever therapy. J. A. M. A., 1937, 109, 2116.

7. McIntosh, R., Kajdi, L., and Meaker, D., The response of plasma, water and electrolytes to elevation of body temperature. Bull. Johns Hopkins Hosp., 1930, 47, 61.

8. Simpson, W. M., Studies on the physiology of fever. J. A. M. A., 1936, 106, 246.

9. Wiggers, C. J., and Orias, O., Circulatory changes during hyperthermia produced by short radio waves (radiothermia). Am. J. Physiol., 1932, 100, 614.

10. Cheer, S. N., Effects of high temperatures on heart and circulation in intact animals. Am. J. Physiol., 1928, 84, 587.

11. Knowlton, F. P., and Starling, E. H., The influence of variations in temperature and blood pressure on the performance of the isolated mammalian heart. J. Physiol., 1912, 44, 206.

12. Asmussen, E., Cardiac output in rest and work in humid heat. Am. J. Physiol., 1940-41, 131, 54.

13. Starr, I., and Jonas, L., Supernormal circulation in resting subjects. Arch. Int. Med., 1943, 71, 1.

14. Huddleston, O. L., Baldes, E. J., and Krusen, F. H., Alterations of cardiac cycle and of polygrams produced by artificial fever. Proc. Soc. Exper. Biol. \& Med., 1939, 42, 1. 